This thesis is submitted in partial fulfillment of the requirements for the degree of

Master of Arts, East Asian Studies

Stanford University

\title{
The Impact of Parental Wealth on the Transition to Homeownership in Urban China
}

\author{
by Ang Yu
}

August 25, 2019

Advisor: Andrew G. Walder

Department: Sociology

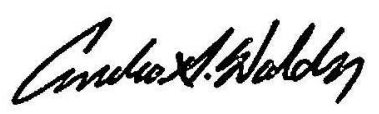

Approval Signature:

Date:

August 25, 2019 


\title{
Table of Contents
}

\author{
i. Abstract \\ ii. Introduction \\ iii. Housing Attainment in Post-reform China \\ iv. Data \\ v. Variables \\ vi. $\quad$ Model \\ vii. Results \\ viii. Summary \\ ix. Limitations \\ x. References
}

\section{Note on Data and Code}

Data used in this thesis are from the China Family Panel Studies and publicly available at http://opendata.pku.edu.cn/dataset.xhtml?persistentId=doi:10.18170/DVN/45LCSO

The data cleaning and statistical analysis are performed in R and Stata, respectively. All results are reproducible and code can be found at https://github.com/angyu/housing_project/blob/master/R-code and https://github.com/angyu/housing_project/blob/master/Stata-code

\section{Acknowledgment}

I would like to thank Andy Walder and Florencia Torche for helpful comments and suggestions. This paper has been presented at the 2018 Asian Conference of the International Chinese Sociological Association at HKUST and the 2019 ISA RC28 Summer Meeting at Princeton. 


\section{Abstract}

Nearly 20 years after the commercialization of housing, the intergenerational dimension of housing attainment in China has not been fully explored. This paper contributes to the literature by examining the impact of parental wealth on adult children's transitions to homeownership. Young people's transitions from renting to owning are conditional on leaving the parental home, and conversely, the prospect of purchasing a self-owned residence within a short period of time may play a role in the decision about moving out. As successive transitions are perhaps interlinked with each other through people's anticipation, I combine a bivariate probit selection model with a discrete time event history analysis to jointly model the timing of nest-leaving and home acquisition. Based on four waves of China Family Panel Survey data, I find that offspring of wealthy parents are more likely to become homeowners and tend to do so sooner than others once they become financially independent from the parental household. In the case of urban China, this paper thereby provides evidence that parents' assets can give offspring a head start in living standards and portfolio build-up during their early adulthood. This paper reveals that housing acquisition is a critical mechanism through which the newly emergent wealth inequality is transmitted across generations in post-socialist China. Additionally, it develops an innovative strategy to address interdependent life course transitions which potentially have broad applications.

\section{Introduction}

A person's housing status influences a wide range of her outcomes: socioeconomic attainment, subjective well-being, demographic transitions, and political engagement (Zavisca and Gerber 2016). In particular, housing wealth occupies a critical position in the growing literature 
on wealth inequality (Killewald, Pfeffer, and Schachner 2017). Often, the largest component of asset holdings for typical households, it is not only a marker of the current store of household wealth, but also a significant source of its future growth (Di, Belsky, and Liu 2007; Killewald and Brielle 2016).

Housing is also a pivotal link in the intergenerational transmission of advantages in wealth. According to Pfeffer and Killeward (2018), homeownership mediates 28 percent of the intergenerational association in net worth in the US. At the micro-level, it has been shown that parental wealth has a significantly facilitative impact on the housing acquisition of offspring in France and Israel (Spilerman 2004; Spilerman and Wolff 2012)․․ Furthermore, a European strand of research reveals a strong intergenerational association in housing tenure (Coulter 2018; Kurz 2004; Mulder and Smits 1999; Öst 2012), which also extends to the multigenerational case (Galster and Wessel 2019). In other words, affluent parents are in a better position to financially support their own children's housing careers.

The direct transfer of resources across generations is a crucial mechanism through which socioeconomically advantaged parents exert impact on offspring's housing attainment. In general, inter vivos gifts and bequests plays an important role in the wealth accumulation of each generation (Adermon, Lindahl, and Waldenström 2018; Boserup, Kopczuk, and Kreiner 2016; Gale and Scholz 1994; Spilerman 2000). In particular, parents' gifts to offspring feature prominently in the explanations of the intergenerational association of homeownership (Helderman and Mulder 2007). More directly, Lee, et al., (2018) have used data in the recent two decades from the US to show

${ }^{1}$ Zavisca (2012:138-42) provided qualitative evidence about how youngsters in post-socialist Russia leverage the propiska system to ensure an inherited home from members of the extended family as purchasing a home on the open market is implausible for many. 
that contemporaneous financial assistance from parents is positively associated with the likelihood of homebuying.

However, Torche and Spilerman (2006) used Chilean data and found an insignificant effect of parental wealth on young couples' transitions to homeownership. Henretta (1984)'s early study also casts doubt on the importance of direct aid from parents in children's home acquisition in the US in 1980. These findings highlight the need to empirically scrutinize the parental impact in specific contexts instead of assuming its universal presence. Indeed, the extent to which homeownership is transmitted across generations appears to vary across cohorts (Coulter 2018; Kurz 2004), periods (Smits and Mulder 2008), and countries (Mulder et al. 2015). Hence, this paper specifically focuses on the case of the young generation of urban residents in contemporary China, where the intergenerational transmission of socioeconomic advantages in the domain of housing has not been extensively studied by sociologists.

Due to the one-child policy, more parents in China are able to direct resources to the only child they have. And as beneficiaries of the socialist housing redistribution system, the older generation almost universally enjoys significant amounts of housing assets themselves. Urbanization of an unprecedented pace and the unique collusion between local governments and land developers produce an upsurge in housing prices so enormous that the majority of young people in cities can never buy a home on their own. Hence, both the supply and demand side considerations lead one to speculate that parental wealth may play a particularly salient role in the housing acquisition of young people in urban China compared to other countries.

\section{Housing Attainment in Post-reform China}


Residence, on average, accounts for more than 70 percent of total household assets and is the primary contributor to the rise in household wealth in China (Li and Wan 2015; Xie and Jin 2015). At the aggregate level, the value of the private housing stock has increased from 60 percent of annual national income in 1991 to 182 percent in 2015 (Novokmet et al. 2018). Therefore, the process of housing attainment is integral to explain the drastic rise in wealth inequality in China (Piketty, Yang, and Zucman 2019). In fact, inequality in housing assets can explain 76 percent of the total household wealth inequality measured by the Gini coefficient (Xie and Jin 2015). Also, the escalation of housing prices could explain $38 \%$ of the increase in wealth inequality between 2002 and 2010 in China (Li and Wan 2015).

In addition, homeownership is viewed as a status good that signals attractiveness in the marriage market (Wei, Zhang, and Liu 2017). Although the positive influence of homeownership on entry to marriage is not consistently confirmed in the US (Gibson-Davis 2009; Schneider 2011), it is still very likely to be present in China. Not surprisingly, homeownership is found to boost owners' subjective well-being in urban China (Cheng et al. 2016; Hu 2013).

China did not have a commercial housing market before the reform of housing commercialization in 1998. In the pre-reform period, urban housing was allocated by work units as welfare items and only associated with a nominal rent. As part of a broader research agenda on the market transition, much scholarly attention has been given to the housing reform process. One line of literature emphasizes the ways in which residential disparities were cemented by the housing reform that heavily subsidized incumbent tenants (Logan, Fang, and Zhang 2010; Walder and $\mathrm{He} 2014)$. Another line of research is framed in terms of the changing importance of political and economic capital in providing housing premia before and after the housing reform, reflecting 
the macro-transition from a redistributive economy to a market economy (Fang and Iceland 2018; Jin and Xie 2017; Meng 2007; Song and Xie 2014; Wu, Bian, and Zhang 2018; Zhao and Ge 2014).

Both approaches of the existing literature are intra-generational in essence. Partly because of the fact that private ownership of housing assets was only legalized two decades ago, there is still little research on the intergenerational dimension of housing attainment in China (X. Wu 2019). The younger cohort of Chinese individuals who entered adulthood after the demise of the public provision of housing has faced a daunting market of real estate. In 2012, the housing price-incomeratio was 6.3 nationally and as high as 16.4 in Shanghai (Ren and Hu 2016). These skyrocketing prices left many young urbanites in China few choices other than to rely on parents' support for housing acquisition. This reality highlights the need to examine the role of parental impact in young people's transitions to homeownership.

Previously, there have been some locality-specific investigations that revealed the importance of parental support in young people's pursuits of a self-owned home in urban China. Li and Shin (2013) collected survey data in Tianjin and found that a large proportion of parents directly transferred housing ownership to children while some also helped children with downpayments, loans, and mortgages. Or's (2017) qualitative study in Beijing documented how propertied parents helped their children with home purchasing via monetary transfers. Wu (2019) uses survey data from Guangzhou and also shows that for the 1980s birth cohort, nearly $80 \%$ of the housing acquisition is achieved with financial help from parents. To my knowledge, the recently published work of Zhu (2018) is so far the only article that taps into the intergenerational aspect of housing attainment in urban China using nationally representative data. The results, based on the 2006 data of China General Social Survey, indicated that relative to individuals' own elite status, fathers' elite status exerted a much stronger influence on the housing status of the former. 
However, that article only inspected the source of ownership and the home value, hence leaving the acquisition of ownership itself out of its scope.

In this paper, I seek to investigate the influence of parental wealth on offspring's odds and the timing of making the transition from renting to owning a home. I expect that parental wealth can expedite children's housing transition to a large extent. In terms of the intertwined life course transitions discussed below, I hypothesize that wealthy offspring may postpone moving out of parental households until they anticipate a fast transition to homeownership thereafter.

Apart from the total effects of parental wealth, I also seek to examine the possible mechanisms through which those effects operate. In this paper, I focus on whether monetary transfers across generations and parental status in housing welfare receipt can explain a portion of the parental wealth effects.

The timing of material support from parents to adult children is often associated with changing circumstances and life events of the children (Leopold and Schneider 2011; Swartz et al. 2011), such as housing purchase. Based on the hypothesis that a significant proportion of parental gifts made immediately before children's home-buying are directed towards that specific purpose, the time-varying amount of intergenerational transfers is incorporated into the event history model. Intuitively, wealthier parents should have more monetary resources to directly transfer to their children, which straightforwardly boost the purchasing power of the later in the housing market.

In the context of contemporary China, especially for the generation who was parents of the respondents in my sample, receiving housing welfare is largely a proxy for state-sector employment. Those employed in the state sector at the initial stage of the housing reform had the chance to purchase the property rights of their residence. At later stages of housing commercialization, resourceful employers in the state sector continued to provide their employees 
with subsidized commercial housing constructed using work units' funds (K. Wu 2019:7). Moreover, it has been shown that state sector employers have the greatest participation rate in housing subsidies and housing provident fund (Gao and Rickne 2014). Receiving housing welfare enables parents to acquire owner-occupied housing at a lower cost for themselves and their children, thus contributing to the wealth accumulation on both parts. By incorporating parental welfare status in analysis, I will examine whether having state-affiliated parents facilitates housing attainment and how much of the parental wealth effects are mediated through parental welfare receipts.

\section{Data}

I make use of China Family Panel Study (CFPS) because it is well-suited for the purposes of this research. Socioeconomic implications of homeownership hinge on the age or stage of life course at which one makes the transition to it. The earlier one makes the transition, the more she can accrue economic gains from the price appreciation of housing assets (Di et al. 2007; Killewald and Brielle 2016) and the faster she can make subsequent transitions that are facilitated by homeownership. In addition, renting is often considered to represent lower standards of living (Spilerman 2004) and bring about lower subjective well-being (Cheng et al. 2016), so the duration of renting among young people is of great concern for the general public and social scientists alike. Therefore, timing matters. The panel data of CFPS from 2010 to 2016 (Xie and Hu 2014) enable me to accurately model the timing of the transition to homeownership in a time-to-event framework.

CFPS also has some unique advantages because of its precise records of housing-related information that otherwise would diminish the interpretability of empirical results. First, CFPS 
enables me to correctly identify all homeowners in the sample even if some of them reside in rented houses at the time of the interview ${ }^{2}$. Second, using CFPS, I am able to differentiate people who live on their own and those who co-reside with parents. Even if these two types of individuals might both live in a home owned by a household member, their housing status should not be regarded as the same ${ }^{3}$. Third, CFPS has information about parents' and offspring's households that were collected from the respective households themselves (Xie and $\mathrm{Hu} 2014$ ), hence supplying a wide range of variables on both sides with relatively less measurement error.

The setup of CPFS, however, poses a methodological challenge. Because of the way the survey was conducted, there are two distinct conceptions about being part of the parents' household. First, one can physically co-reside with parents. Second, one can be financially dependent on parents. In the datasets of CFPS, only when one becomes financially independent from her previous household will she have a separate economic questionnaire which collects information about living arrangements. According to the criteria of CFPS, being financially independent of the parental home is conditional on having physically left it and ultimately determined by the respondent's own judgment. Therefore, the transition of tenancy status from renting to owning only becomes observable when the respondent indicates that she has physically and financially left the parental home. Hence comes the sample selection problem.

Aside from the technical problem that non-random sample selection poses for causal estimation of the effect of parental wealth, the interdependent structure between two transitions of the life course is revealing in own rights. In demographic research, multiple life course transitions

\footnotetext{
${ }^{2}$ For example, some people may rent out their primary residences and dwell in a rented home in order to live close to their workplaces or their children's schools.

${ }^{3}$ An unpublished working paper (Niu and Zhao, 2018) using China Household Finance Survey made this mistake.
} 
are often simply juxtaposed, leaving the interdependence among them un-modeled (eg. Billari, Hiekel, and Liefbroer 2019). There are two existing approaches of modeling that do take into account the relationship between transitions (Wu 2003) but still misses what the sample selection framework can offer. Multiple time dimensions, such as age and duration starting from a previous life course event can be represented in event history models by two parameters. However, the endogenous selection into the previous life course event is assumed away in this case. The other approach model multiple transitions in the spirit of simultaneous equation models. This framework deals with the interlinked-ness of transitions in a way similar to the approach I propose in this paper, but entering the risk set for each transition is not conditional on making another transition in the pre-existing framework.

Therefore, I set up the analytic sample in a way that addresses the sample selection and time-to-event natures of the research question simultaneously. Respondents who were financially in the same household with at least one parent in the baseline wave of the survey in 2010 are included in the full sample used for modeling the selection into financial independence. Then respondents who no longer shared households with either parent in a subsequent wave (in 2012, 2014, or 2016) enter the selected sample used for modeling the housing transition.

I impose several necessary restrictions on the data. First, the sample is restricted to those who were born between 1976 and 1998, so all individuals in the sample were not older than 40 and not younger than 18 as of 2016, the last year of the observation window. I only focus on the younger generation because housing transition is part of demographic transitions typically experienced in early- and mid-adulthood. In addition, older generations in China are almost universally assigned with state-built housing, hence only the younger generation has enough variations in the outcome variable. Second, only those who financially belonged to the parental 
household in 2010, the baseline year, enter the sample, because the timing information of the twostage transitions is only available for this group of people. In addition, I have dropped respondents whose parents' IDs differ across survey waves. List-wise deletion is conducted to respondents (respondent-years) missing on variables in the model.

\section{Variables}

The outcome variable is the occurrence of the transition to homeownership in a specific year, coded as a time-varying binary variable. Those whose current residence is self-owned, coowned with the work unit, or provided by relatives are considered owners, as are those who have a self-owned residential property elsewhere, regardless of the ownership status of their current residence. Housing provided by relatives is treated as owner-occupied to avoid underestimating the influence of parental aid because parents may offer the residence without formally transferring the ownership right to the recipient. Conversely, those living in rented homes or in flats provided by the work unit or the government free of charge are considered non-owners.

The key independent variable of interest is the asset holdings of the parental household, namely the net worth of the household the respondent financially belonged to when the baseline interview was conducted in $2010^{4}$. I use two continuous measures for it: the percentile rank of the net worth of the respondent's baseline household among all households in the full sample and the inverse hyperbolic sine transformed net worth (Friedline, Masa, and Chowa 2015). Both of these two measures can preserve the full range of wealth distribution without raising the need to drop negative or zero values. Furthermore, the ownership of a second-home in 2010, which is a binary

\footnotetext{
${ }^{4}$ The time-varying version of the independent variable is discussed below.
} 
variable, is also used as an alternative measure of household assets. These measures are denoted as Wealth Percentile, IHS Wealth, and Second Home, respectively.

Independence is the first-stage dependent variable, indicating whether the individual is selected into the sample used for estimating the housing transition. Independence represents being financially independent of the parental home, conditional on having physically done so. In addition, only those who dwelled in the urban area when they became financially independent are coded to $1 \mathrm{in}$ this variable. This is for the sake of reducing heterogeneity caused by fundamentally different housing markets in urban and rural areas ${ }^{5}$. In the analytic sample, $12.37 \%(687 / 5601)$ respondents made the first-stage transition during the observation window.

A serials of control variables are included in the models.

Parental variables:

Parental Education: father's educational attainment. There are four categories: primary school or less (baseline category), junior high school, senior high school, college or above. Missing values are substituted by mother's educational attainment. Parental Age: father's age. Missing values are substituted by mother's age plus two as the mean gap between father's age and mother's age is around two years in the sample. The parental age variable is recoded to be missing if the parent is not at least 16 years older than the respondent. Parental Age Squared: the squared term of the previous variable. In order to reduce co-linearity, the age variable is centered around its mean. Parental Party Membership: whether either one of the parents has Chinese Communist Party membership. This variable is used to measure the political capital of the family. Parental

\footnotetext{
${ }^{5}$ Note that because of the way independence is coded, rural-to-urban migration will also make a respondent "becomes independent" and vice versa, even if the respondent has been financially independent before the migration. At the same time, merely becoming financially independent but remain a rural resident does not make one selected into the second stage risk set. In other words, what the selection variable actually indicates is selection into the urban housing market.
} 
Bad Health: whether at least one parent has a self-assessed poor health condition. Parental Employment: whether at least one parent is employed at the time of the survey. Parental Coresidence: whether both parents physically co-reside with the respondent. Family Size: the total number of members in the financially-defined parental household. Parental Questionnaire Missing: whether the respondent misses at least one parent's questionnaire which might impact the measurement of Parental Bad Health, Parental Employment, and Parental Housing Welfare ${ }^{67}$.

Own variables:

Male: the respondent's gender, with female coded as the reference. Married: the respondent's own marital status. Urban Origin: the respondent's baseline household was in an urban area according to the urban-rural designation of the national statistical bureau. Wave: three categories representing 2012, 2014, and 2016, namely the three available waves of follow-up surveys. Age and Age Squared: similarly centered as the parental age variables. Number of Siblings: the number of children of the respondent's parents who financially belonged to the parental household in the baseline year as well. A few cases where the number of children is incongruent between the father's side and the mother's side are dropped. Education: the same four categories as in parental education. Log Income PC: the log-transformed yearly net household income per capita, based on the adjusted version in CFPS ${ }^{8}$. Have Child: whether the respondent has her own

\footnotetext{
${ }^{6}$ Some respondents may have a parent with poor health, an employed parent, or a parent with housing welfare but treated otherwise due to parent missing questionnaire. By including Parental Questionnaire Missing, I control for the potential impact of this.

${ }^{7}$ Note that the respondent's own baseline employment, housing welfare, and health status are not included in the models. This is only because if they are, the loss of sample size due to missing values among respondents will be infeasibly large.

${ }^{8}$ Although I put Income Percentile under individual variables in the results tables, note that for the baseline wave, Income Percentile may only reflect either the respondent's, her parents', or both of their contributions to the household net income, depending on who are earners at that time.
} 
child. Co-residence: the respondent physically lived in the financially defined parental household in the baseline year.

To investigate channels through which parental wealth exerts influence, there are two "intermediate" variables included in supplementary models. Parental Housing Welfare: whether either one parent has received any welfare item that facilitates the acquisition of owner-occupied housing. Those welfare items include privatized work-unit housing, commercial housing subsidized by the work unit, housing subsidy, housing provident fund, and renting subsidy. Housing welfare information was only collected in the first wave, hence this variable is measured at the baseline. Transfer: whether the respondent receives financial transfers from relatives. This variable is a proxy for receiving monetary transfers from parents, although contributions made by relatives other than parents are also reflected in this variable. As the timing of the transfer is hypothesized to concur with that of home-buying, this mediator is only measured as a non-lagged time-varying variable and only appears in the time-varying version of the model.

The selection and outcome variable are time-varying. For the sake of parsimony, once the respondent made the transition to financial independence, she enters and stays in the selected sample regardless of whether she subsequently turned dependent again. Analogously, once one made the transition to homeownership, she drops out of the risk set irrespective of whether she remained a homeowner in all years after that. Table 1 and Table 2 show the actual number of respondents who made and reversed the transitions in each year and the extent of coding imprecision can be gauged accordingly.

In the main analysis, all predictors of the two-stage equations are treated as time-constant and drawn from baseline questionnaires. This treatment is predicated on four considerations. First, this prevents conditioning on a post-treatment mediator that may give rise to endogenous selection 
bias (Elwert and Winship 2014; Gelman and Hill 2006:188-92). Second, as the housing transition is itself a cause of a wide range of socioeconomic and demographic outcomes (Zavisca and Gerber 2016), using baseline measures also minimizes the possibility of reverse causality. Third, as the window of observation is relatively short, the true values of covariates can be reasonably assumed constant. Fourth, the covariates in later waves tend to have high proportions of missing values, causing a significant loss of statistical power if used. To test how sensitive the results are to this specification, I additionally conduct analyses allowing as many covariates to vary across waves as possible.

In the time-varying version models, log per capita family income is measured contemporaneously with the dependent and key independent variables and serves as an additional instrumental variable that only appears in the outcome equation but not the selection equation. Meanwhile, the baseline family income is still included in the model, reflecting the income of the parental household while the respondent was still financially in the parental household. Therefore, the time-varying family income measures the impact of the income flow in the newly-formed household of the respondent herself, net of the baseline income in her original household. Parental wealth is measured as the lagged average wealth of the household that father and mother are respectively in each year, no matter whether the respondent is in the same household or not ${ }^{9}$. If the mother and father belong to the same household, the measure reduces to the wealth of the household shared by mother and father. The same time-varying specification applies to all three measures of parental wealth ${ }^{10}$.

\footnotetext{
${ }^{9}$ Therefore, under this specification, parental wealth in the second stage equation strictly measures the assets of the parental household where the respondent no longer resides.

${ }^{10}$ For the indicator of second home ownership, there are only 15 person-years that do not have either value 1 or zero (they are 0.5 ), and I recode them to be 1 .
} 
In order to minimize the possibility of reversed causation, other time-varying variables are also lagged by one wave ${ }^{11}$. Two groups of variables have different specifications from each other. The first group is the control variables Married, Education, Have Child, Parental Employment, Parental Bad Health, and Parental Questionnaire Missing. For this group of variables that appear in both selection and outcome equations, I use straightforwardly constructed lagged terms and all respondents in all waves have time-varying values on these variables. The other group is the instrumental variables that only appear in the selection equation, including Co-residence, Family Size, Co-residence, Urban Origin, and Parental Co-residence. For the second group, variables are only time-varying to the point where the respondent becomes financially independent. For instance, for someone who becomes independent in 2014, values of 2010 appear in the row corresponding to wave 2012, values of 2012 appear in the row corresponding to wave 2014, and row 2016 also has 2012 variable values ${ }^{12}$. Coded in this way, value changes in these instrumental variables only affect the probability of selection in each wave but not the outcome after being selected. Other variables are assumed to be time-constant ${ }^{13}$.

Table 1. Number of respondents leaving and returning the parental home in each year

\begin{tabular}{llll}
\hline & 2012 & 2014 & 2016 \\
\hline Become independent & 135 & 432 & 522 \\
Become dependent & & 28 & 116 \\
\hline
\end{tabular}

${ }^{11}$ The reason time-varying family income is not lagged is that it is used as an instrumental variable that is only allowed to operate for the independent households of the respondents themselves. By using the contemporaneous form, the impact of this variable is restricted to be on the outcome and not on the selection.

${ }^{12}$ For those who never become independent during the observational window, there is no difference between these two groups of variables.

${ }^{13}$ Number of Siblings, Age, Age Squared, Parental Education, Parental Age, Parental Age Squared, Parental Party Membership, and Parental Housing Welfare. Note that complete information about Parental Housing Welfare is only available in the baseline wave. 
Note: $\mathrm{N}=5601$ (persons, not person-years)

Table 2. Number of respondents acquiring and losing homeownership in each year

\begin{tabular}{llll}
\hline & 2012 & 2014 & 2016 \\
\hline Acquire Ownership & 84 & 140 & 196 \\
Lose Ownership & & 19 & 68 \\
\hline
\end{tabular}

Note: $\mathrm{N}=5601$ (persons, not person-years)

\section{Model}

My modeling strategy takes into account both the sample selectivity and time-to-event characteristics of the research question. First, the sample selection issue is addressed by a Heckman style selection model. Individuals and households make their decisions about critical life-course transitions with a strong inclination to first anticipate the impact of one transition on subsequent transitions in the future and act upon that anticipation. Moreover, people may have different levels of innate resistance to renting, which is unobserved. For those with a stronger psychological aversion to renting, leaving parental home will be delayed based on personal choice and moving into owner-occupation will be conversely accelerated. Therefore, it is reasonable to construe decisions about successive transitions as jointly made and endogenously entwined with each other. In the case of this paper, individuals may decide the timing of the transition to financial independence on the basis of the prospect of buying a home within a short period of time. Researches in the UK (Ermisch and Di Salvo 1997) and Hong Kong (Ting and Chiu 2002) have found that the higher the housing prices relative to wages, the latter young people's departure from 
the parental home ${ }^{14}$. A piece of more direct evidence is that the perceived unaffordability of housing has a delaying effect on home-leaving in the Netherlands (Billari and Liefbroer 2007) ${ }^{1516}$.

Second, a discrete time event history model is employed to reflect the time-to-event nature of the research question. The outcome, therefore, is the occurrence of the transition to homeownership in a specific year after the respondent's transition to financial independence. Respondents who had not made the transition to homeownership at the end of the observation window, 2016, are treated as right-censored. Coupled with a Heckman selection model, the event history analysis properly captures the real-world social processes in which temporal decisions about successive transitions are jointly made. Essentially, what is modeled here is the duration of the interval between becoming financially independent and becoming a homeowner. The onset of this interval serves as the dependent variable in the first stage of the sample selection model while its ending serves as the dependent variable in the second stage. Compared to a competing risk framework that only captures a single transition, this modeling strategy supplies critical information about the length of renting. The model is the same as what was proposed by Holm and Jæger (2011) for educational transitions in sequence, except that here the data consist of person-

${ }^{14}$ Using CFPS data, $\mathrm{Li}$ and $\mathrm{Wu}(2018)$ investigated the effect of city-level housing prices on intergenerational co-residence and obtain corroborative results. However, their findings were not very interpretable as they did not differentiate young people moving out of the parental home and elderly parents in need of care moving into offspring's residence.

${ }^{15}$ An analogous finding is that greater expectations for divorce predict slower entry into marriage in the United States (Arocho 2019).

${ }^{16}$ People coming from different family backgrounds may differ in the way they make such anticipation-based decisions. For example, wealthy offspring may be more sensitive to tenure type and inclined to delay nest-leaving until they are financially ready to purchase a home. This surmise is consistent with both the relative risk aversion theory (Breen and Goldthorpe 1997; Holm and Jæger 2008) and the socialization theory of intergenerational association of housing status (Mulder and Smits 1999), which postulate that children of better-off origins have a strong incentive to at least maintain the social status and living standards of their parents. However, empirically examine this pattern is beyond the scope of this research. 
years instead of persons ${ }^{17}$. Most recently, van den Berg et. al (2018) also employed a similar approach that combined an event history analysis with a bivariate probit selection model to examine the interlinked processes of leaving and returning to the parental home.

In terms of estimation, the selection model here consists of a probit model at each of the two stages and assumes bivariate normality. The models are estimated by a Full Information Maximum Likelihood procedure (Dubin and Rivers 1989) partly because of the pitfalls of the twostage estimator that was originally developed by Heckman (Stolzenberg and Relles 1997). Standard errors are clustered at the level of the baseline household ${ }^{18}$. To aid identification, several "instrumental variables" are included in the selection equation but not in the outcome equation (Winship and Mare 1992). These variables are respondents' age and its squared term, family size, physical co-residence, urban origin, and parental co-residence.

The use of age is based on the consideration that after marriage and childbearing are controlled for, the age norm should still operate for nest-leaving but not for home-buying. Billari and Liefbroer (2007)'s article combined a Heckman selection model with a Cox Proportional Hazards model to study the transition out of one's parental home and age was also used as an excluded instrumental variable ${ }^{19}$. As for the binary instrumental variables, urban origin and parental co-residence are implicitly part of the definition of the selection variable as only urbandwelling respondents not financially co-residing with either parent are considered independent.

\footnotetext{
${ }^{17}$ For joint models applied in educational transitions, also see (Holm and Breen 2016)

${ }^{18}$ Hence, siblings who left the parental home and either lived together or separately are treated as in the same cluster. This setup is based on the fact that baseline covariates are measured at the household level.

${ }^{19}$ However, if the exclusion restriction is not actually satisfied, bias will still be generated (Winship and Mare 1992). In addition, the structural assumption of bivariate normality is also rather strong and has been challenged by methodologists (eg. McGovern et al. 2015). Therefore, the results may be sensitive to specifications and should be interpreted with caution.
} 
Although not definitionally part of the selection process, family size and physical co-residence also measure characteristics of the parental household that affect how proximate it is for the respondent to become financially independent. On the other hand, they should not have any direct effect on the outcome, homeownership, net of their effect on the first stage transition. Of course, I acknowledge that the appropriateness of any variable as an instrumental variable is debatable and caution should be exerted when interpreting results ${ }^{20}$.

\section{Results}

Table 3. Coefficients of Bivariate Probit Selection Models, Percentile Measure

\begin{tabular}{|c|c|c|c|c|}
\hline & $\begin{array}{l}\text { Model 1, } \\
\text { Independence }\end{array}$ & $\begin{array}{l}\text { Model 1, } \\
\text { Ownership }\end{array}$ & $\begin{array}{l}\text { Model 2, } \\
\text { Independence }\end{array}$ & $\begin{array}{l}\text { Model 2, } \\
\text { Ownership }\end{array}$ \\
\hline \multicolumn{5}{|l|}{ Individual variables } \\
\hline Male & $-0.24 * * *$ & -0.20 & $-0.25 * * *$ & -0.16 \\
\hline \multicolumn{5}{|l|}{ Wave } \\
\hline Second Wave & $0.58 * * *$ & $-0.76 * * *$ & $0.58 * * *$ & $-0.78 * * *$ \\
\hline Third Wave & $0.91 * * *$ & $-1.19 * * *$ & $0.92 * * *$ & $-1.25 * * *$ \\
\hline \multicolumn{5}{|l|}{ Education } \\
\hline Junior High & $0.12 *$ & 0.10 & $0.13 *$ & 0.03 \\
\hline Senior High & $0.32 * * *$ & 0.08 & $0.34 * * *$ & -0.05 \\
\hline College or above & $0.53 * * *$ & 0.33 & $0.56 * * *$ & 0.12 \\
\hline Log Income PC & -0.03 & $0.13 * *$ & 0.02 & 0.06 \\
\hline Married & $-0.24 * * *$ & $0.41 *$ & $-0.24 * *$ & $0.40 *$ \\
\hline Have Child & 0.06 & -0.16 & 0.07 & -0.17 \\
\hline \multicolumn{5}{|l|}{ Parental variables } \\
\hline Wealth Percentile & & & $-0.35 * * *$ & $0.41 *$ \\
\hline Age & & & -0.01 & -0.00 \\
\hline Age Sqr & & & 0.00 & -0.00 \\
\hline \multicolumn{5}{|l|}{ Education } \\
\hline Junior High & & & 0.06 & 0.01 \\
\hline Senior High & & & -0.07 & -0.05 \\
\hline
\end{tabular}

${ }^{20}$ There are some methodological developments that aim to circumvent the exclusion restriction of Heckman style models. However, they either make even stronger assumptions that are unlikely to hold in the present case (Sartori 2003) or require a continuous outcome variable (eg. Lee 2009). 
College or above

Party Membership

Bad Health

Employment

Number of Siblings

Miss Questionnaire

Instrumental

variables

\begin{tabular}{|c|c|c|c|c|}
\hline Age & $0.05 * * *$ & & $0.06^{* * *}$ & \\
\hline Age Sqr & $-0.00 * * *$ & & $-0.00 * * *$ & \\
\hline Family Size & 0.02 & & $0.03 *$ & \\
\hline Co-residence & $-0.27 * * *$ & & $-0.25 * * *$ & \\
\hline Parental Coresidence & -0.02 & & -0.03 & \\
\hline Urban Origin & $0.19 * * *$ & & $0.23 * * *$ & \\
\hline Constant & $-1.73 * * *$ & 0.04 & $-2.06 * * *$ & 1.04 \\
\hline Rho & -0.22 & -0.22 & -0.41 & -0.41 \\
\hline Chi2 & 122.60 & 122.60 & 154.38 & 154.38 \\
\hline AIC & 8797.32 & 8797.32 & 8783.00 & 8783.00 \\
\hline $\mathrm{N}$ & 17603 & 1122 & 17603 & 1122 \\
\hline
\end{tabular}

Notes: $* * * \mathrm{p}<0.001 ; * * \mathrm{p}<0.01 ; * \mathrm{p}<0.05$. Each observation represents a person-year. Observations are clustered at the baseline household level for the calculation of standard errors.

Table 3 presents two nested Bivariate Probit Selection Models. Model 1 only contains the respondent's basic demographic variables while Model 2 also includes control variables of parents and specifically, parental wealth measured by net worth percentile rank. Clearly, parental wealth percentile has a significantly accelerative effect on offspring's process of home acquisition. Therefore, the role of parental wealth is both statistically significant and substantively important. At the same time, parental wealth percentile's effect on the independence status of adult children is significantly negative.

This pattern is consistent with my expectation that young people who are economically better-off tend to delay their nest-leaving until they are financially ready to purchase their own home within a short period of time. Note that these effects of parental wealth hold even after controlling for an extensive set of covariates on the part of the offspring and their parents. 
According to Chi-Square and AIC statistics, the inclusion of parental variables improves the model fit.

As the rho statistic shows, there is a negative correlation between the error term of the outcome equation and the selection equation. In model 1, if respondent's education is not controlled for, the rho statistic will become significant (not shown). This implies a negative selection on unobserved variables, which is also expected because these unobserved factors, such as the psychological penchant for owner-occupation and aversion to rental tenancy, conceivably operate in a similar way to parental wealth, hence deterring home-leaving but facilitating homebuying.

If negative selectivity is not adequately dealt with, upwardly biased estimates of coefficients in the outcome equation will be generated (Holm and Jæger 2011; Stolzenberg and Relles 1997). Nevertheless, it appears the selectivity issue is well accounted for by the observed covariates in the model and a selection model may be actually unnecessary given such specification in this case. In supplementary analysis (Table 7), I also added interaction terms between parental wealth and children' gender to both stages of the model. Both interaction terms are statistically insignificant, suggesting the pattern discussed above is not differentiated by gender.

Table 4. Coefficients of Bivariate Probit Selection Models, Alternative Measures

\begin{tabular}{|c|c|c|c|c|}
\hline & $\begin{array}{l}\text { Model 3, } \\
\text { Independence }\end{array}$ & $\begin{array}{l}\text { Model 3, } \\
\text { Ownership }\end{array}$ & $\begin{array}{l}\text { Model 4, } \\
\text { Independence }\end{array}$ & $\begin{array}{l}\text { Model 4, } \\
\text { Ownership }\end{array}$ \\
\hline \multicolumn{5}{|l|}{ Individual variables } \\
\hline Male & $-0.24 * * *$ & -0.18 & $-0.24 * * *$ & -0.19 \\
\hline \multicolumn{5}{|l|}{ Wave } \\
\hline Second Wave & $0.58 * * *$ & $-0.77 * * *$ & $0.58 * * *$ & $-0.77 * * *$ \\
\hline Third Wave & $0.92 * * *$ & $-1.22 * * *$ & $0.92 * * *$ & $-1.12 * * *$ \\
\hline \multicolumn{5}{|l|}{ Education } \\
\hline Junior High & $0.12^{*}$ & 0.06 & $0.12 *$ & 0.06 \\
\hline Senior High & $0.32 * * *$ & -0.01 & $0.32 * * *$ & -0.02 \\
\hline College or above & $0.54 * * *$ & 0.18 & $0.54 * * *$ & 0.18 \\
\hline Log Income PC & -0.02 & 0.09 & -0.02 & $0.10^{*}$ \\
\hline
\end{tabular}




$\begin{array}{lllll}\text { Married } & -0.24 * * & 0.40^{*} & -0.24 * * * & 0.40 \\ \text { Have Child } & 0.06 & -0.13 & 0.05 & -0.13\end{array}$

\section{Parental variables}

\begin{tabular}{|c|c|c|c|c|}
\hline IHS Wealth & -0.01 & 0.02 & & \\
\hline Second Home & & & -0.03 & $0.27^{*}$ \\
\hline Age & -0.01 & -0.00 & -0.01 & -0.00 \\
\hline Age Sqr & 0.01 & -0.00 & 0.00 & -0.00 \\
\hline \multicolumn{5}{|l|}{ Education } \\
\hline Junior High & 0.05 & 0.02 & 0.05 & 0.02 \\
\hline Senior High & -0.07 & -0.04 & -0.07 & -0.08 \\
\hline College or above & -0.18 & -0.08 & -0.18 & -0.10 \\
\hline Party Membership & -0.00 & 0.16 & 0.00 & 0.18 \\
\hline Bad Health & -0.02 & 0.06 & -0.01 & 0.05 \\
\hline Employment & -0.03 & -0.04 & -0.03 & -0.04 \\
\hline Number of Siblings & 0.02 & -0.07 & 0.02 & -0.08 \\
\hline Miss Questionnaire & -0.03 & -0.12 & -0.03 & -0.12 \\
\hline \multicolumn{5}{|l|}{$\begin{array}{l}\text { Instrumental } \\
\text { variables }\end{array}$} \\
\hline Age & $0.06 * * *$ & & $0.06 * * *$ & \\
\hline Age Sqr & $-0.00 * * *$ & & $-0.00 * * *$ & \\
\hline Family Size & 0.02 & & 0.02 & \\
\hline Co-residence & $-0.27 * *$ & & $-0.27 * * *$ & \\
\hline Parental Coresidence & -0.04 & & -0.04 & \\
\hline Urban Origin & $0.21 * * *$ & & $0.21 * * *$ & \\
\hline Constant & $-1.77 * * *$ & 0.55 & $-1.81 * * *$ & 0.81 \\
\hline Rho & -0.35 & -0.35 & -0.38 & -0.38 \\
\hline Chi2 & 146.36 & 146.36 & 143.54 & 143.54 \\
\hline AIC & 8808.98 & 8808.98 & 8807.42 & 8807.42 \\
\hline $\mathrm{N}$ & 17600 & 1122 & 17600 & 1122 \\
\hline
\end{tabular}

Table 4 presents the results based on alternative measures of parental wealth. The effect of the IHS transformed net worth does not attain statistical significance, though the directions of the effects remain the same (the small magnitude of the coefficient is largely a result of scaling). As for second-home ownership, it is found to significantly improve the likelihood and timing of 
obtaining a self-owned home, corroborating results based on percentile rank measure. It is not clear whether the IHS transformed net worth captures substantively difference aspect of parental wealth.

In Table 5, the percentile rank measure of parental wealth has negatively significant effect on home-leaving and positively significant effect on home-buying, suggesting time-constant and time-varying specifications of independent variables and certain covariates do not make a substantive difference. Notably, in the time-varying model with parental covariates, the correlation coefficient between equations reaches statistical significance, which might be attributed to either the time-varying specification or the inclusion of own family income as an instrumental variable.

Besides, married individuals are consistently more likely to make the transition to homeownership at a faster rate. Thus, research on the effect of homeownership on marriage in China should carefully consider the possibility of reverse causality.

Exploratory analyses regarding mechanism are shown in Table 7 and Table 8. Both parental housing welfare receipt and children's receipt of intergenerational transfers have no significant effect themselves and the coefficients of parental wealth only changes slightly compared to models without these two mediators. Hence, little evidence is present for substantial mediation effects on the part of these two variables. However, mediation effects in the context of a longitudinal study with time-varying selection and confounders can involve complex causal structure. Therefore, the null findings here with regard to mediators should be viewed with caution.

Table 5. Coefficients of Bivariate Probit Selection Models, Time-Varying Variables

Model 1, Model 1, Model 2, Model 2,
Independence Ownership Independence Ownership

\section{Individual variables}

Male

$-0.21 * * *$

-0.21 *

$-0.22 * * *$

$-0.16$

Wave

Second Wave

$0.42^{* * *}$

$-0.93 * * *$

$0.43^{* * *}$

$-0.90^{* * *}$ 
Third Wave

$0.89 * * *$

$-1.29 * * *$

$0.85 * * *$

$-1.35 * * *$

Education

Junior High

$0.17 * *$

0.17

$0.18 * * *$

0.07

Senior High

$0.20 * *$

0.09

$0.23 * * *$

$-0.04$

College or above

$0.54 * * *$

0.34

$0.58 * * *$

0.11

Log Income PC -

baseline

$-0.04$

$0.13^{* *}$

0.01

0.05

Married

0.07

$0.47 * *$

0.07

$0.41 * *$

Have Child

-0.20 **

0.06

$-0.19 * *$

0.08

\section{Parental variables}

Wealth Percentile

Age

Age Sqr

Education

Junior High

Senior High

College or above

Party Membership

Bad Health

Employment

Number of Siblings

Miss Questionnaire

\section{Instrumental}

variables only in the selection equation

Age

Age Sqr

Family Size

Co-residence

Parental Coresidence

Urban Origin

Instrumental

variables only in the outcome equation

Log Income PC - later waves

Constant

Rho

Chi2

AIC

$\mathrm{N}$
$0.05 * * *$

$-0.00 * * *$

0.01

$-0.26 * * *$

$-0.36 * * *$

$0.20 * * *$

$\begin{array}{ll}-0.29 * * * & 0.37 * \\ -0.01 * & 0.00 \\ 0.00 & -0.00\end{array}$

0.05

0.01

$-0.09$

0.02

$-0.20$

$-0.09$

0.01

$0.32 *$

0.06

$-0.14$

0.12 *

0.14

0.02

$-0.12 *$

-0.20 **

0.02

$0.07 * * *$

$-0.00 * * *$

0.01

$-0.24 * * *$

$-0.37 * * *$

$0.28 * * *$

$-0.08$

0.82

$-0.30$

132.44

8067.83

976
$-0.10 *$

$-1.84 * * *$

$2.10 * *$

$-0.48 *$

$-0.48 *$

160.07

160.07

7566.89

7566.89

976 
Notes: $* * * \mathrm{p}<0.001 ; * * \mathrm{p}<0.01 ; * \mathrm{p}<0.05$. Each observation represents a person-year. Observations are clustered at the baseline household level for the calculation of standard errors. The sample size here is different from the time-constant version because list-wise deletion due to missingness differs.

\section{Limitations}

First, my measures of asset holdings of the parental household are very likely to consist of adult children's contributions. This is partly because that the way CFPS defines financial independence makes more adult children designated as part of their parents' households than a coresidence-based definition would. If the measures of parental net worth also capture children's own achieved financial well-being, the parental impact would be overestimated. However, no matter how adult children's own household is defined, the contemporaneous measures of parental wealth are always at the risk of being contaminated by financial inflows from children. Unfortunately, there is no measure of parental wealth during respondents' childhood in CFPS.

The second limitation is closely related to the first. In the model that does not contain a measure of parental wealth (not shown), neither parents' human and political capital nor offspring's human capital has a significant effect on the latter's homeownership. If a simple binary outcome model is used without the correction for sample selectivity, then the educational attainment of adult children, but not any status variable of parents, has a significantly positive impact on home-buying. Hence, it is not clear what are the ultimate determinants of home-buying that exert their impact through the accumulated assets of the household the respondent originally belonged to.

Third, the definition of financial independence in CFPS is idiosyncratic and varies with each respondent' own subjective evaluation of her (in)dependency status. This exacerbates the difficulty of identifying instrumental variables as it is not easy to conceive of covariates that meaningfully exert monotonic effects on an idiosyncratically defined status for all respondents. 
Fourth, the four-year window of observation is rather short. This not only prevents me from observing long-term trends of housing attainment but also renders subgroup analyses difficult. I suspect that the parental impact on adult children's housing tenures is only salient when the latter are migrants dwelling in metropolitan areas where the rental sector thrives, and housing prices far exceed earnings of most young workers.

Fifth, the current coding scheme of the outcome and the selection variable is not precise because once the individual makes the transition at each stage, she is coded to remain in the posttransition state irrespective of whether she subsequently returns to financial dependence or renting (see table 1 and table 2). Even if the subsequent states of outcome and selection could be precisely coded, the first stage model will still lack a conventional interpretation in the time-to-event framework because those who become independent but do not buy a home immediately will always have more than one person-year that has value 1 in the selection variable.

\section{Summary}

The contributions of this paper are twofold. First, using up-to-date and nationally representative data, it sheds light on a previously understudied dimension of the economic wellbeing of young people and the intergenerational transmission of advantages in China. Second, it innovatively examines successive life-course transitions using a bivariate probit sample selection model and shows a way to take into account people's anticipation at the time of making transitional decisions.

The findings indicate that parental wealth significantly increases young adults' chances of acquiring a self-owned home and shortens the renting period for them in urban China. This result is robust to alternative measures of parental assets, time-wise specifications, and an extensive set of control variables. Therefore, it is worthwhile to bring the intergenerational perspective to the 
research on wealth and housing inequality in China. Since the onset of housing commercialization reform two decades ago, Chinese cities have witnessed a booming market of residential real estate and the rapid stratification of housing wealth among urbanites. With the wealth amassed in the post-reform era of China, affluent parents not only invest in their children's human capital and leverage social capital to boost the latter's socioeconomic standings but also directly assist their adult children at critical junctures of wealth accumulation throughout the life course. Those who are lucky to have affluent parents, then, are given a head start in the build-up of their own wealth and can enjoy higher standards of living than their peers in early adulthood. In the case of housing, which constitutes a substantial part of household wealth and is socially coveted, I have provided evidence of the intergenerational reproduction of household wealth and economic well-being.

People constantly anticipate the potential consequences of their immediate choices and make the decision according to that anticipation at key life junctures. Across the life course, transitionary decisions are intertwined with one another because the probability of successfully achieving the subsequent transitions affects the decision of making the earlier transition in the first place. With regard to home-buying and leaving one's parental home, unobserved factors, including people's anticipation and expectation, that impact the likelihood and timing of home-buying may also be associated with the likelihood and timing of home-leaving. Hence, the use of a sample selection model in the study of successive life-course transitions corrects for an important source of selection bias and provides more insights about temporally structured mechanisms behind social actors' decision-making. Although empirically I find that after controlling for certain variables, the sample selection model is no longer necessary for the particular research question in this paper, the sample selection model may still fruitfully add to life-course studies in other domains and other contexts (for analogous applications, see van den Berg et al. 2018; Holm and Jæger 2011). 
Table 7. Coefficients of Bivariate Probit Selection Models, with Gender by Parental wealth Interaction

\begin{tabular}{|c|c|c|}
\hline & $\begin{array}{l}\text { Model 1, } \\
\text { Independence }\end{array}$ & $\begin{array}{l}\text { Model 1, } \\
\text { Ownership }\end{array}$ \\
\hline \multicolumn{3}{|l|}{ Individual variables } \\
\hline Male & $-0.30 * * *$ & -0.13 \\
\hline Male*Parental Wealth & 0.10 & -0.06 \\
\hline \multicolumn{3}{|l|}{ Wave } \\
\hline Second Wave & $0.58^{* * *}$ & $-0.78 * * *$ \\
\hline Third Wave & $0.92^{* * *}$ & $-1.24 * * *$ \\
\hline \multicolumn{3}{|l|}{ Education } \\
\hline Junior High & $0.13^{*}$ & 0.04 \\
\hline Senior High & $0.34^{* * *}$ & -0.05 \\
\hline College or above & $0.56^{* * *}$ & 0.12 \\
\hline Log Income PC - baseline & 0.02 & 0.06 \\
\hline Married & $-0.24 * *$ & $0.40^{*}$ \\
\hline Have Child & 0.07 & -0.17 \\
\hline \multicolumn{3}{|l|}{ Parental variables } \\
\hline Wealth Percentile & $-0.41 * * *$ & 0.45 \\
\hline Age & -0.01 & -0.00 \\
\hline Age Sqr & 0.00 & -0.00 \\
\hline \multicolumn{3}{|l|}{ Education } \\
\hline Junior High & 0.06 & 0.01 \\
\hline Senior High & -0.07 & -0.05 \\
\hline College or above & -0.15 & -0.11 \\
\hline Party Membership & 0.00 & 0.15 \\
\hline Bad Health & -0.03 & 0.07 \\
\hline Employment & -0.01 & -0.05 \\
\hline Number of Siblings & 0.02 & -0.07 \\
\hline Miss Questionnaire & -0.03 & -0.12 \\
\hline \multicolumn{3}{|c|}{$\begin{array}{l}\text { Instrumental variables only in the selection } \\
\text { equation }\end{array}$} \\
\hline Age & $0.06^{* * *}$ & \\
\hline Age Sqr & $-0.00 * * *$ & \\
\hline Family Size & 0.03 & \\
\hline Co-residence & $-0.25 * * *$ & \\
\hline Parental Coresidence & -0.03 & \\
\hline Urban Origin & $0.23^{* * *}$ & \\
\hline
\end{tabular}


Instrumental variables only in the outcome equation

Log Income PC - later waves

$-0.08$

Constant

$-2.03^{* * *} \quad 1.01$

Rho

$-0.41$

$-0.30$

Chi2

154.62

154.62

AIC

8786.23

8786.23

17600

1122

Notes: $* * * \mathrm{p}<0.001 ; * * \mathrm{p}<0.01 ; * \mathrm{p}<0.05$. Each observation represents a person-year.

Observations are clustered at the baseline household level for the calculation of standard errors.

Table 8. Coefficients of Bivariate Probit Selection Models with Parental Housing Welfare, Time-Constant Specification

\begin{tabular}{|c|c|c|}
\hline & Model 1, Independence & Model 1, Ownership \\
\hline \multicolumn{3}{|l|}{ Individual variables } \\
\hline Male & $-0.25 * * *$ & -0.17 \\
\hline \multicolumn{3}{|l|}{ Wave } \\
\hline Second Wave & $0.58 * * *$ & $-0.77 * * *$ \\
\hline Third Wave & $0.92 * * *$ & $-1.23 * * *$ \\
\hline \multicolumn{3}{|l|}{ Education } \\
\hline Junior High & $0.13 *$ & 0.04 \\
\hline Senior High & $0.34 * * *$ & -0.04 \\
\hline College or above & $0.56 * * *$ & 0.14 \\
\hline Log Income PC & 0.02 & 0.05 \\
\hline Married & $-0.24 *$ & $0.43^{*}$ \\
\hline Have Child & 0.07 & -0.17 \\
\hline \multicolumn{3}{|l|}{ Parental variables } \\
\hline Wealth Percentile & $-0.35^{*}$ & $0.40^{*}$ \\
\hline Age & -0.01 & -0.00 \\
\hline Age Sqr & 0.00 & 0.00 \\
\hline \multicolumn{3}{|l|}{ Education } \\
\hline Junior High & 0.06 & 0.01 \\
\hline Senior High & -0.06 & -0.07 \\
\hline College or above & -0.14 & -0.22 \\
\hline Party Membership & 0.01 & 0.13 \\
\hline Bad Health & -0.03 & 0.07 \\
\hline Employment & -0.01 & -0.07 \\
\hline Number of Siblings & 0.01 & -0.06 \\
\hline Miss Questionnaire & -0.03 & -0.12 \\
\hline
\end{tabular}


Housing Welfare

$-0.05$

0.36

\section{Instrumental variables}

$\begin{array}{lll}\text { Age } & 0.06 * * * & \\ \text { Age Sqr } & -0.00^{* * *} & \\ \text { Family Size } & 0.03 * & \\ \text { Co-residence } & -0.25 * * * & \\ \text { Parental Coresidence } & -0.03 & -2.07 * * * \\ \text { Urban Origin } & 0.24 * * * & -0.40 \\ \text { Constant } & 1.04 & 155.62 \\ \text { Rho } & -0.40 & 8782.92 \\ \text { Chi2 } & 155.62 & 1122 \\ \text { AIC } & 8782.92 & \\ \mathrm{~N} & 17600 & \end{array}$

Notes: ${ }^{* * *} \mathrm{p}<0.001 ; * * \mathrm{p}<0.01 ; * \mathrm{p}<0.05$. Each observation represents a person-year.

Observations are clustered at the baseline household level for the calculation of standard errors.

Table 9. Coefficients of Bivariate Probit Selection Models with Intergenerational Transfer, Time-Varying Specification

\begin{tabular}{|c|c|c|}
\hline & $\begin{array}{l}\text { Model 1, } \\
\text { Independence }\end{array}$ & $\begin{array}{l}\text { Model 1, } \\
\text { Ownership }\end{array}$ \\
\hline \multicolumn{3}{|l|}{ Individual variables } \\
\hline Male & $-0.21 * * *$ & -0.16 \\
\hline \multicolumn{3}{|l|}{ Wave } \\
\hline Second Wave & $0.43 * * *$ & -0.88 \\
\hline Third Wave & $0.84 * * *$ & -1.36 \\
\hline \multicolumn{3}{|l|}{ Education } \\
\hline Junior High & $0.19 * *$ & 0.08 \\
\hline Senior High & $0.24 * * *$ & -0.08 \\
\hline College or above & $0.58 * * *$ & 0.11 \\
\hline Log Income PC - baseline & 0.01 & 0.03 \\
\hline Married & 0.07 & $0.42 * * *$ \\
\hline Have Child & $-0.19 * *$ & 0.07 \\
\hline \multicolumn{3}{|l|}{ Parental variables } \\
\hline Wealth Percentile & $-0.32 * * *$ & $0.44 * *$ \\
\hline Age & $-0.01 *$ & 0.00 \\
\hline Age Sqr & 0.00 & -0.00 \\
\hline \multicolumn{3}{|l|}{ Education } \\
\hline Junior High & 0.05 & -0.00 \\
\hline Senior High & -0.08 & 0.02 \\
\hline
\end{tabular}


College or above

Party Membership

0.00

0.31 *

Bad Health

0.06

$-0.14$

Employment

0.11 *

0.15

Number of Siblings

0.01

$-0.11 *$

Miss Questionnaire

$-0.23 * * *$

0.04

Transfer

0.19

0.19

Instrumental variables only in the selection equation

Age

$0.07 * * *$

Age Sqr

$-0.000 * * *$

Family Size

0.02

Co-residence

$-0.24 * * *$

Parental Coresidence

$-0.36 * * *$

Urban Origin

$0.28 * * *$

Instrumental variables only in the outcome equation

Log Income PC - later waves

$-0.08$

Constant

$-1.86 *$

$2.06^{* *}$

Rho

$-0.48 *$

$-0.48 *$

Chi2

164.87

164.87

AIC

7761.22

7761.22

16438

1122

Notes: $* * * \mathrm{p}<0.001 ; * * \mathrm{p}<0.01 ; * \mathrm{p}<0.05$. Each observation represents a person-year. Observations are clustered at the baseline household level for the calculation of standard errors.

\section{References}

Adermon, Adrian, Mikael Lindahl, and Daniel Waldenström. 2018. "Intergenerational Wealth Mobility and the Role of Inheritance: Evidence from Multiple Generations." The Economic Journal 128(612):F482-513.

Arocho, Rachel. 2019. "Do Expectations of Divorce Predict Union Formation in the Transition to Adulthood?" Journal of Marriage and Family jomf.12571.

van den Berg, Lonneke, Matthijs Kalmijn, and Thomas Leopold. 2018. "Leaving and Returning Home: A New Approach to Off-Time Transitions: Leaving and Returning Home." Journal of Marriage and Family. 
Billari, Francesco C., Nicole Hiekel, and Aart C. Liefbroer. 2019. "The Social Stratification of Choice in the Transition to Adulthood." European Sociological Review.

Billari, Francesco C. and Aart C. Liefbroer. 2007. "Should I Stay or Should I Go? The Impact of Age Norms on Leaving Home.” Demography 44(1):181-98.

Boserup, Simon H., Wojciech Kopczuk, and Claus T. Kreiner. 2016. "The Role of Bequests in Shaping Wealth Inequality: Evidence from Danish Wealth Records.” American Economic Review 106(5):656-61.

Breen, Richard and John Goldthorpe. 1997. "Explaining Educational Differentials: Towards a Formal Rational Action Theory." Rationality and Society 9(3):275-305.

Cheng, Zhiming, Stephen P. King, Russell Smyth, and Haining Wang. 2016. "Housing Property Rights and Subjective Wellbeing in Urban China." European Journal of Political Economy 45:160-74.

Coulter, Rory. 2018. "Parental Background and Housing Outcomes in Young Adulthood." Housing Studies 33(2):201-23.

Di, Zhu Xiao, Eric Belsky, and Xiaodong Liu. 2007. "Do Homeowners Achieve More Household Wealth in the Long Run?” Journal of Housing Economics 16(3-4):274-90.

Dubin, Jeffrey A. and Douglas Rivers. 1989. "Selection Bias in Linear Regression, Logit and Probit Models." Sociological Methods \& Research 18(2-3):360-390.

Elwert, Felix and Christopher Winship. 2014. "Endogenous Selection Bias: The Problem of Conditioning on a Collider Variable." Annual Review of Sociology 40(1):31-53.

Ermisch, John and Pamela Di Salvo. 1997. "The Economic Determinants of Young People's Household Formation.” Economica 64(256):627-44.

Fang, Changchun and John Iceland. 2018. "Housing Inequality in Urban China: The Heritage of Socialist Institutional Arrangements.” The Journal of Chinese Sociology 5(1).

Friedline, Terri, Rainier D. Masa, and Gina A. N. Chowa. 2015. "Transforming Wealth: Using the Inverse Hyperbolic Sine (IHS) and Splines to Predict Youth's Math Achievement." Social Science Research 49:264-87.

Gale, William G. and John Karl Scholz. 1994. "Intergenerational Transfers and the Accumulation of Wealth." Journal of Economic Perspectives 8(4):145-60.

Galster, George and Terje Wessel. 2019. "Reproduction of Social Inequality through Housing: A Three-Generational Study from Norway.” Social Science Research 78:119-36.

Gao, Qin and Johanna Rickne. 2014. "Firm Ownership and Social Insurance Inequality in Transitional China: Evidence from a Large Panel of Firm-Level Data.” European Journal of Social Security 16(1):2-25. 
Gelman, Andrew and Jennifer Hill. 2006. Data Analysis Using Regression and Multilevel Hierarchical Models. Cambridge University Press.

Gibson-Davis, Christina M. 2009. "Money, Marriage, and Children: Testing the Financial Expectations and Family Formation Theory." Journal of Marriage and Family 71(1):146-60.

Helderman, Amanda and Clara Mulder. 2007. "Intergenerational Transmission of Homeownership: The Roles of Gifts and Continuities in Housing Market Characteristics." Urban Studies 44(2):231-47.

Henretta, John C. 1984. "Parental Status and Child's Home Ownership." American Sociological Review 49(1):131.

Hitlin, Steven and Monica Kirkpatrick Johnson. 2015. "Reconceptualizing Agency within the Life Course: The Power of Looking Ahead.” American Journal of Sociology 44.

Holm, Anders and Richard Breen. 2016. "Behavioral and Statistical Models of Educational Inequality." Rationality and Society 28(3):270-98.

Holm, Anders and Mads Meier Jæger. 2008. "Does Relative Risk Aversion Explain Educational Inequality? A Dynamic Choice Approach." Research in Social Stratification and Mobility 26(3):199-219.

Holm, Anders and Mads Meier Jæger. 2011. "Dealing with Selection Bias in Educational Transition Models: The Bivariate Probit Selection Model." Research in Social Stratification and Mobility 29(3):311-22.

Hu, Feng. 2013. "Homeownership and Subjective Wellbeing in Urban China: Does Owning a House Make You Happier?” Social Indicators Research 110(3):951-71.

Jin, Yongai and Yu Xie. 2017. "Social Determinants of Household Wealth and Income in Urban China." Chinese Journal of Sociology 3(2):169-92.

Killewald, Alexandra and Bryan Brielle. 2016. "Does Your Home Make You Wealthy?" RSF: The Russell Sage Foundation Journal of the Social Sciences 2(6):110.

Killewald, Alexandra, Fabian T. Pfeffer, and Jared N. Schachner. 2017. "Wealth Inequality and Accumulation." Annual Review of Sociology 43(1):379-404.

Kurz, K. 2004. "Labour Market Position, Intergenerational Transfers and Home-Ownership: A Longitudinal Analysis for West German Birth Cohorts." European Sociological Review 20(2):141-59.

Lee, David S. 2009. "Training, Wages, and Sample Selection: Estimating Sharp Bounds on Treatment Effects." REVIEW OF ECONOMIC STUDIES 32. 
Lee, Hyojung, Dowell Myers, Gary Painter, Johanna Thunell, and Julie Zissimopoulos. 2018. "The Role of Parental Financial Assistance in the Transition to Homeownership by Young Adults." Journal of Housing Economics.

Leopold, T. and T. Schneider. 2011. "Family Events and the Timing of Intergenerational Transfers." Social Forces 90(2):595-616.

Li, Bingqin and Hyun Bang Shin. 2013. "Intergenerational Housing Support Between Retired Old Parents and Their Children in Urban China." Urban Studies 50(16):3225-42.

Li, Lixing and Xiaoyu Wu. 2018. "Housing Price and Intergenerational Co-Residence in Urban China." Journal of Housing Economics.

Li, Shi and Haiyuan Wan. 2015. "Evolution of Wealth Inequality in China." China Economic Journal 8(3):264-87.

Logan, John R., Yiping Fang, and Zhanxin Zhang. 2010. “The Winners in China's Urban Housing Reform.” Housing Studies 25(1):101-17.

McGovern, Mark E., Till Bärnighausen, Giampiero Marra, and Rosalba Radice. 2015. "On the Assumption of Bivariate Normality in Selection Models: A Copula Approach Applied to Estimating HIV Prevalence." Epidemiology 26(2):229-37.

Meng, Xin. 2007. "Wealth Accumulation and Distribution in Urban China." Economic Development and Cultural Change 55(4):761-91.

Mulder, C. H. and J. Smits. 1999. "First-Time Home-Ownership of Couples The Effect of InterGenerational Transmission.” European Sociological Review 15(3):323-37.

Mulder, Clara H., Caroline Dewilde, Mark van Duijn, and Annika Smits. 2015. "The Association Between Parents' and Adult Children's Homeownership: A Comparative Analysis." European Journal of Population 31(5):495-527.

Novokmet, Filip, Thomas Piketty, Li Yang, and Gabriel Zucman. 2018. "From Communism to Capitalism: Private versus Public Property and Inequality in China and Russia." AEA Papers and Proceedings 108:109-13.

Or, Tsz-ming. 2017. "Pathways to Homeownership among Young Professionals in Urban China: The Role of Family Resources." Urban Studies 004209801771421.

Öst, Cecilia Enström. 2012. "Parental Wealth and First-Time Homeownership: A Cohort Study of Family Background and Young Adults' Housing Situation in Sweden." Urban Studies 49(10):2137-52.

Pfeffer, Fabian T. and Alexandra Killewald. 2018. "Generations of Advantage. Multigenerational Correlations in Family Wealth.” Social Forces 96(4):1411-42. 
Piketty, Thomas, Li Yang, and Gabriel Zucman. 2019. "Capital Accumulation, Private Property, and Rising Inequality in China, 1978-2015." American Economic Review 109(7):246996.

Ren, Qiang and Rongqin Hu. 2016. "Housing Inequality in Urban China.” Chinese Journal of Sociology 2(1):144-67.

Sartori, Anne E. 2003. "An Estimator for Some Binary-Outcome Selection Models Without Exclusion Restrictions." Political Analysis 11(02):111-38.

Schneider, Daniel. 2011. "Wealth and the Marital Divide." American Journal of Sociology 117(2):627-67.

Smits, Annika and Clara H. Mulder. 2008. "Family Dynamics and First-Time Homeownership." Housing Studies 23(6):917-33.

Song, Xi and Yu Xie. 2014. "Market Transition Theory Revisited: Changing Regimes of Housing Inequality in China, 1988-2002.” Sociological Science 1:277-91.

Spilerman, Seymour. 2000. "Wealth and Stratification Processes." Annual Review of Sociology 26(1):497-524.

Spilerman, Seymour. 2004. "The Impact of Parental Wealth on Early Living Standards in Israel." American Journal of Sociology 110(1):92-122.

Spilerman, Seymour and Francois-Charles Wolff. 2012. "Parental Wealth and Resource Transfers: How They Matter in France for Home Ownership and Living Standards." Social Science Research 41(2):207-23.

Stolzenberg, Ross M. and Daniel A. Relles. 1997. "Tools for Intuition about Sample Selection Bias and Its Correction." American Sociological Review 62(3):494.

Swartz, Teresa Toguchi, Minzee Kim, Mayumi Uno, Jeylan Mortimer, and Kirsten Bengtson O'Brien. 2011. "Safety Nets and Scaffolds: Parental Support in the Transition to Adulthood." Journal of Marriage and Family 73(2):414-29.

Ting, Kwok-fai and Stephen W. K. Chiu. 2002. "Leaving the Parental Home: Chinese Culture in an Urban Context." Journal of Marriage and Family 64(3):614-26.

Torche, Florencia and Seymour Spilerman. 2006. "Parental Wealth Effects on Living Standards and Asset Holdings: Results from Chile." in International Perspectives on Household Wealth. Edward Elgar Publishing.

Walder, Andrew G. and Xiaobin He. 2014. "Public Housing into Private Assets: Wealth Creation in Urban China.” Social Science Research 46:85-99.

Wei, Shang-Jin, Xiaobo Zhang, and Yin Liu. 2017. "Home Ownership as Status Competition: Some Theory and Evidence.” Journal of Development Economics 127:169-86. 
Winship, Christopher and Robert D. Mare. 1992. "Models for Sample Selection Bias." Annual Review of Sociology 18:327-50.

Wu, Kaize. 2019. "Housing Reform, Life Course and Urban Housing Acquisition (1980-2010)." The Journal of Chinese Sociology 6(1).

Wu, Lawrence L. 2003. "Event History Models for Life Course Analysis." Pp. 477-502 in Handbook of the life course. Boston, MA: Springer.

Wu, Lili, Yang Bian, and Wei Zhang. 2018. "Housing Ownership and Housing Wealth: New Evidence in Transitional China." Housing Studies 1-21.

Wu, Xiaogang. 2019. "Inequality and Social Stratification in Post-Socialist China." Annual Review of Sociology.

Xie, Yu and Jingwei Hu. 2014. "An Introduction to the China Family Panel Studies (CFPS)." Chinese Sociological Review 47(1):3-29.

Xie, Yu and Yongai Jin. 2015. "Household Wealth in China." Chinese Sociological Review 47(3):203-29.

Zavisca, Jane R. 2012. Housing the New Russia. Ithaca: Cornell University Press.

Zavisca, Jane R. and Theodore P. Gerber. 2016. "The Socioeconomic, Demographic, and Political Effects of Housing in Comparative Perspective." Annual Review of Sociology 42(1):347-67.

Zhao, Wei and Jianhua Ge. 2014. "Dual Institutional Structure and Housing Inequality in Transitional Urban China." Research in Social Stratification and Mobility 37:23-41.

Zhu, Ling. 2018. "Intergenerational Housing Asset Transfer and the Reproduction of Housing Inequality in Urban China." Chinese Journal of Sociology 2057150X1879283. 